\title{
CATECHINS OF THE BARK OF LARIX SIBIRICA
}

\author{
L. T. Pashinina, T. K. Chumbalov, and Z. A. Leiman
}

Khimiya Prirodnykh Soedinenii, Vol. 6, No. 4, p. 478, 1970

UDC 547.972

In the bark of Larix sibi rica (Siberian larch) we have detected four compounds giving the reaction with vanillin in conc $\mathrm{HCl}$ that is characteristic for catechins and having the following $\mathrm{R}_{f}$ values: in a butan-1-ol-acetic acid-water system $0.94,0.83,0.70$, and 0.64 ; and in $2 \%$ acetic acid $0.35,0.30,0.34$, and 0.28 . On treatment with $p-$ toluenesulfonic acid, these substances appear on the chromatograms in the form of yellow spots, while the action of diazotized p-nitroaniline forms brown colorations. Substances 1 and 2 are not revealed on chromatograms by ammonium ferric alum, while 3 and 4 give green colors.

The flavonoids were extracted from the bark by methanol after elimination of the waxes and resins with petroleum ether and benzene. The tanning substances were eliminated from the methanolic extract by precipitation with ether. The ethereal methanolic solution was evaporated to dryness and the dry residue was dissolved in ether. The phenolic acids were separated by treating the ethereal solution with sodium bicarbonate. The separation of the hydroxyflavones and their purification from flavonols and flavanonols was carried out by partition chromatography on silica gel using ether as the mobile solvent. The first fractions contained the flavonols and flavanonols [1]. Then the hydroxyflavones 1-4 were eluted successively. No sharp boundaries between the zones were observed. However, on rechromatography catechins 3 and 4 were isolated in the individual state. They were recrystallized from water. Catechin 2 was separated from resins and from substance 1 by chromatography on cellulose with water as the eluent. Catechin 2 precipitated from the aqueous eluate in the form of faintly yellowish prismatic crystals with mp $250-252^{\circ} \mathrm{C}$ (under the microscope). After chromatography on Sephadex G-25, the aqueous solution yielded crystals in the form of fine colorless needles with mp $252-253^{\circ} \mathrm{C}$ (under the microscope).

The properties of catechins 3 and 4 correspond to those of $(+)$-catechin and (-)-epicatechin as given in the literature $[2,3]$. It must be mentioned that the $(-)$-epicatechin is present in the bark in trace amounts. Catechin 2 was identified as (-)-3, 5, 7, 4'-tetrahydroxyflavane [(-)-epiafzelechin]. This compound (mp $240-243^{\circ} \mathrm{C}$ ) was found previously by King et al. [4] in the wood of Afzelia. The other physical constants of this substance and its derivatives and their IR and UV spectra coincide with the properties given in the literature. In addition to King's data, we determined the specific rotation of the tetraacetyl derivative $\left(\mathrm{mp} 126-128^{\circ} \mathrm{C}\right),[\alpha]_{\mathrm{D}}^{23}-19.2^{\circ}(0.6$, acetone). Compound 1 proved to be a new flavonoid; its study is continuing.

\section{REFERENCES}

1. T. K. Chumbalov, L. T. Pashinina, and Z. A. Leiman, KhPS [Chemistry of Natural Compounds], 3, $216,1967$.

2. K. Freudenberg and L. Purrman, Ann., 437, 274, 1924.

3. T. K. Chumbalov and L. T. Pashinina, Biokhim. , 27, 651, 1962.

4. F. E. King and I. W. Clark-Lewis, J. Chem. Soc., 2948, 1955.

18 May 1970

Kirov Kazakh State University 